\title{
Plant Genomics
}

Edited by: Hany A. El-Shemy

University of Cairo, Egypt

Published: April 2009. Pages: 100

ISBN: Book: 978-1-912530-06-9 £159, \$319

Published by: Caister Academic Press www.caister.com

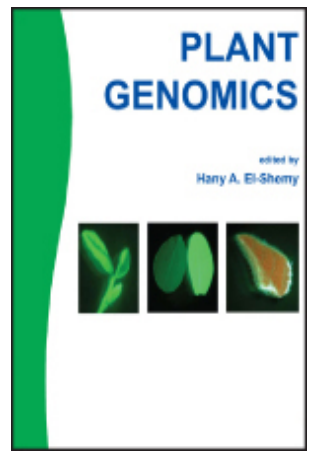

The editor of this timely book has assembled a team of highly regarded scientists, over 40 contributors, to describe the latest, up-to-date research, theory and applications of this increasingly important area of science.

Renowned experts in the field have contributed chapters that describe and discuss some of the most topical aspects of plant genomics. The book is fully illustrated and chapters include comprehensive reference sections.

Essential reading for scientists involved in plant genomics and a recommended volume for everyone involved in plant science.

Chapter 1. A High-Resolution Melting Approach for Analyzing Allelic Expression Dynamics (Jiazheng Yuan, Muhammad Haroon, David Lightfoot, Yvan Pelletier, Qiang Liu and Xiu-Qing Li)

Chapter 2. Multigeneic QTL: The Laccase Encoded within the Soybean Rfs2/rhg1 Locus Inferred to Underlie Part of the Dual Resistance to Cyst Nematode and Sudden Death Syndrome (M.J. Iqbal, R. Ahsan, A.J. Afzal, A. Jamai, K. Meksem, H.A. El- Shemy and D.A. Lightfoot)

Chapter 3. The Role of Green Fluorescent Protein (GFP) in Transgenic Plants to Reduce Gene Silencing Phenomena (Hany A. El-Shemy, Mutasim M. Khalafalla and Masao Ishimoto)

Chapter 4. Antisense Phenotypes Reveal a Functional Expression of OsARF1, an Auxin Response Factor, in Transgenic Rice (Kotb A. Attia, Amr F. Abdelkhalik, Megahed H. Ammar, Chun Wei, Jinshui Yang, David A. Lightfoot, Wagih M. El-Sayed and Hany A. El-Shemy)

Chapter 5. An Account of Cloned Genes of Methyl-erythritol-4-phosphate Pathway of Isoprenoid Biosynthesis in Plants (Deepak Ganjewala, Shiv Kumar and Rajesh Luthra)

Chapter 6. Establishment of the Regeneration System for Vicia faba L. (Shimaa Bahgat, Omer A. Shabban, Osama El-Shihy, David. A. Lightfoot and Hany A. El- Shemy)

Chapter 7. Cloning of a Novel Antifungal Promoter from Phaseolus vulgaris and the Determination of its Activity in Stably Transformed Nicotiana tabacum Plants (Eman A. Mahmoud, Solliman M. Mohei El-Din, Mourad A. M. Aboul-Soud, Ahmed M. Aboul-Enein, Ghanem A. Sobhy and Hany A. El-Shemy)

Chapter 8. The Interactions of the Largest Subunit of RNA Polymerase II with Other Cellular Proteins: a Bioinformatic Approach (Abhijit Shukla, Aparna Natarajan, Sukesh Bhaumik, Hany A. El-Shemy and David Lightfoot) Chapter 9. Locus Interactions Underlie Seed Yield In Soybeans Resistant to Heterodera glycines (U.B. Karangula, M.A. Kassem, L. Gupta, H.A. El-Shemy and D.A. Lightfoot)

Chapter 10. Different Responses of Two Genes Associated with Disease Resistance Loci in Maize (Zea mays L.) to 3-allyloxy-1,2-benzothiazole 1,1-dioxide (Jiazheng Yuan, Jennifer Tedman, Liakat Ali, Jie Liu, Jeff Taylor, David Lightfoot, Michiaki Iwata and K. Peter Pauls)

\section{Order from:}

Caister Academic Press https://www.caister.com/order 
Plant Genomics

Edited by: Hany A. El-Shemy (Published: 2009)

Microbial Ecology: Current Advances from Genomics, Metagenomics and Other Omics

Edited by: Diana Marco (Published: 2019)

Plant-Microbe Interactions in the Rhizosphere

Edited by: Adam Schikora (Published: 2018)

Prions: Current Progress in Advanced Research (Second Edition)

Edited by: Akikazu Sakudo and Takashi Onodera (Published: 2019)

Microbiota: Current Research and Emerging Trends

Edited by: Takashi Matsumoto and Yoshio Yamaoka, (Published: 2019)

Porcine Viruses: From Pathogenesis to Strategies for Control

Edited by: Hovakim Zakaryan (Published: 2019)

Lactobacillus Genomics and Metabolic Engineering

Edited by: Sandra M. Ruzal (Published: 2019)

the most relevant aspects of the more than 200 recognized species of

the Lactobacillus genus

Cyanobacteria: Signaling and Regulation Systems

Author: Dmitry A. Los (Published: 2018)

Viruses of Microorganisms

Edited by: Paul Hyman and Stephen T. Abedon (Published: 2018)

Protozoan Parasitism: From Omics to Prevention and Control

Edited by: Luis Miguel de Pablos Torró and Jacob-Lorenzo Morales (Published: 2018)

Genes, Genetics and Transgenics for Virus Resistance in Plants

Edited by: Basavaprabhu L. Patil (Published: 2018)

DNA Tumour Viruses: Virology, Pathogenesis and Vaccines

Edited by: Sally Roberts (Published: 2018)

Pathogenic Escherichia coli: Evolution, Omics, Detection and Control

Edited by: Pina M. Fratamico, Yanhong Liu and Christopher H. Sommers (Published: 2018)

Postgraduate Handbook: A Comprehensive Guide for PhD and Master's Students and their Supervisors Author: Aceme Nyika (Published: 2018)

Enteroviruses: Omics, Molecular Biology, and Control

Edited by: William T. Jackson and Carolyn B. Coyne (Published: 2018)

"frontiers in the study of the 12 species of the genus" (ProtoView); "the current most important enterovirus research"

(Biotechnol. Agron. Soc. Environ.)

Molecular Biology of Kinetoplastid Parasites

Edited by: Hemanta K. Majumder (Published: 2018)

"I would therefore recommend this book" (Parasites and Vectors)

Bacterial Evasion of the Host Immune System

Edited by: Pedro Escoll (Published: 2017)

"The figures are expertly drawn" (SIMB News)

Illustrated Dictionary of Parasitology in the Post-Genomic Era

Author: Hany M. Elsheikha and Edward L. Jarroll (Published: 2017)

"a guide for students, academic staff, medical and veterinarian professionals" (ProtoView); "an extensive and comprehensive glossary of contemporary concepts, terminologies, and vocabulary in modern parasitology" (Doodys); "a pure pleasure to explore and discover" (Epidemiol. Infect.); "highly recommended" (Biotechnol. Agron. Soc. Environ.) 